\title{
Utilização de vermicomposto como substrato na produção de mudas de Eucalyptus grandis e Corymbia citriodora
}

\author{
Gerusa Pauli Kist Steffen ${ }^{1}$, Zaida Inês Antoniolli', Ricardo Bemfica Steffen ${ }^{1}$, Gustavo Schiedeck ${ }^{2}$ \\ 1'Departamento de Solos, Centro de Ciências Rurais, Universidade Federal de Santa Maria (UFSM), Camobi, 1.000, CEP 97105-900, Santa Maria, RS, Brasil. \\ ${ }^{2}$ Embrapa Clima Temperado, Rodovia BR 392, Km 78, CP 403, CEP 96010-971, Pelotas, RS, Brasil.
}

"Autor correspondente:

ge.pauli@yahoo.com.br

Termos para indexação:

Essências florestais

Substrato orgânico

Eucalipto

Index terms:

Forest species

Organic substrate

Eucalyptus

Histórico do artigo:

Recebido em 08 abr 2011

Aprovado em 16 jun 2011

Publicado em 30 jun 2011

doi: 10.4336/2011.pfb.31.66.75
Resumo - Avaliou-se a eficiência do vermicomposto na produção de mudas de duas espécies de eucalipto. $\mathrm{O}$ experimento foi conduzido em casa de vegetação, utilizandose substratos constituídos por diferentes proporções de vermicomposto e turfa para a produção de mudas de E. grandis e C. citriodora. O delineamento experimental foi inteiramente casualizado com sete tratamentos e oito repetições. Decorridos 100 dias após sua implantação, avaliaram-se os parâmetros: altura da planta, biomassa da parte aérea fresca e seca, volume radicular, biomassa das raízes secas e o índice de qualidade de Dickson (IQD). O tratamento constituído por $80 \%$ de vermicomposto apresentou os melhores resultados nos parâmetros altura das mudas, volume radicular e biomassa seca da parte aérea e de raízes. Para a espécie C. citriodora, a adição de vermicomposto à turfa nas proporções de $40 \%$ a $80 \%$ mostrou-se eficiente no crescimento das mudas, sendo que a primeira proporção proporcionou maior altura e massa seca da parte aérea das mudas, e a segunda, maior volume radicular. As proporções $60 \%$ e $80 \%$ de vermicomposto adicionadas à turfa favorecem a produção de mudas de E. grandis e C. citriodora.

\section{Use of vermicompost as a substrate for the production of Eucalyptus grandis and Corymbia citriodora seedlings}

\begin{abstract}
The aim of this work was to evaluate the vermicompost efficiency in the seedlings of two eucalyptus species production. The experiment was developed in greenhouse conditions, substrate constituted by different vermicompost proportions and peat for the $E$. grandis and $C$. citriodora seedling production. The experimental design was entirely casualized with seven treatments and eight repetitions. After 100 days of experiment were evaluated: seedling height, fresh and dry biomass of aerial part, root volume, dry biomass of the root and Dickson quality index (DQI). The treatment constituted by $80 \%$ vermicompost and $20 \%$ peat presented the highest results in height, root volume and dry mass of the aerial part and roots. For the species $C$. citriodora was observed that the vermicompost addition to the peat in the proportions from $40 \%$ to $80 \%$ was shown efficient in the seedlings growth. The treatment constituted by $80 \%$ vermicompost and $20 \%$ peat provided highest height and dry mass of the aerial part seedlings and the treatment constituted by $60 \%$ vermicompost and $40 \%$ peat provided highest root volume. The proportions $60 \%$ and $80 \%$ vermicompost added to the peat increase the E. grandis and C. citriodora seedlings production.
\end{abstract}




\section{Introdução}

Devido à crescente demanda de matéria-prima do setor florestal, a silvicultura vem buscando medidas eficazes para aumentar a produtividade das essências florestais, aumentando os seus níveis de produção para atender a demanda resultante do crescimento demográfico (Embrapa Florestas, 2003). Em decorrência disso, pesquisas sobre as alternativas tecnológicas para a produção de mudas de qualidade estão se intensificando.

Para o melhoramento da produção de mudas florestais, os substratos têm se destacado como um importante insumo agrícola pela sua ampla utilização no sistema produtivo de mudas e influência direta no desempenho das plantas no campo (Kämpf, 2000). Na produção de mudas de qualidade, é indispensável a utilização de substratos que ofereçam, principalmente, boas características físicas e químicas, com boa estrutura, consistência, alta porosidade, alta capacidade de retenção e fornecimento de água e nutrientes (Moraes Neto et al., 2001).

O vermicomposto, material formado por substâncias orgânicas complexas e estáveis, resultante da atividade e interação de minhocas com microrganismos que habitam seu trato digestivo, influencia direta e indiretamente o crescimento de plantas, devido a quantidades significativas de ácidos húmicos e hormônios reguladores do crescimento vegetal (Antoniolli et al., 1996; Benítez et al., 2000; Atiyeh et al., 2002; Antoniolli et al., 2002; Brown et al., 2004; Arancon et al., 2006). Além disto, a utilização de vermicomposto em substratos resulta em incremento na população microbiana e na biodisponibilização de nutrientes minerais para as plantas (Gamaley et al., 2001; Ndeqwa \& Thompson, 2001; Atiyeh et al., 2002). Segundo Abreu Júnior et al. (2005) e Arancon et al. (2006), além dos benefícios causados pela estimulação da microbiota presente no substrato decorrente da ação de hormônios presentes no vermicomposto, substratos constituídos por compostos orgânicos estáveis podem causar supressividade sobre alguns fitopatógenos fúngicos e bacterianos. Desta forma, a utilização de vermicomposto como constituinte de substratos, além de suprir as necessidades nutricionais das plantas, contribui para o controle de determinados fitopatógenos.

O vermicomposto é considerado um bioestimulador do crescimento vegetal (Aquino \& Nogueira, 2001; Edwards, 2004). No entanto, o efeito verificado nas plantas depende de sua viabilidade, da matéria-prima original, do nível de estabilização, da dose utilizada e da espécie vegetal (Steffen et al., 2010). Após o processamento dos resíduos orgânicos pelas minhocas e sua transformação em vermicomposto, observa-se uma estabilização da acidez e alta capacidade de troca catiônica, resultando na formação de uma fração estável, o que assegura ao vermicomposto bons resultados quando utilizado como substrato no cultivo de plantas (Oliveira et al., 2001).

Nos últimos anos, a utilização de vermicomposto misturado a outros materiais para a constituição de substratos tem apresentado resultados promissores na produção de mudas hortícolas, ornamentais e de algumas espécies florestais (Caldeira et al., 2000; Oliveira et al., 2001; Vogel et al., 2001; Atiyeh et al., 2002; VielmaRondón et al., 2003; Edwards, 2004; Arancon et al., 2006; Steffen et al., 2010).

Caldeira et al. (2000), avaliando a utilização de vermicomposto na mistura de casca de Pinus sp. e vermiculita, observaram que a adição de vermicomposto ao substrato proporcionou maiores valores para altura de mudas, diâmetro do caule e biomassa radicular e aérea de mudas de Eucalyptus saligna Smith.

No caso das essências florestais, os trabalhos apresentados na literatura evidenciam o efeito benéfico do vermicomposto na produção de mudas em proporções de até $50 \%$ em relação a outros substratos. Neste sentido, o objetivo deste trabalho foi avaliar a utilização de vermicomposto e turfa para produção de mudas de Eucalyptus grandis W. Hill ex Maiden e Corymbia citriodora Hill \& Johnson em proporções de 0 a $100 \%$.

\section{Material e métodos}

O vermicomposto utilizado no experimento para a constituição dos substratos foi obtido através do processo de vermicompostagem de esterco curtido de bovinos criados em sistema de confinamento, por meio da atividade de minhocas da espécie Eisenia andrei Bouché (1972). Os tratamentos foram constituídos por vermicomposto e turfa (Tabela 1) em diferentes proporções, utilizando-se o critério volume por volume $(\mathrm{v} / \mathrm{v})$. Testaram-se sete combinações: tratamento controle com $100 \%$ de turfa e $100 \%$ de vermicomposto e tratamentos com $20 \%, 40 \%, 60 \%$ e $80 \%$ de vermicomposto, respectivamente. Utilizou-se o delineamento experimental inteiramente casualizado, 
com oito repetições, constituídas de dez plantas por repetição.

As misturas foram realizadas com os componentes levemente umedecidos para facilitar a homogeneização manual dos mesmos e evitar a perda de substrato pelos orifícios dos tubetes. O umedecimento do substrato antes do enchimento dos tubetes também objetivou evitar a redução do espaço poroso, visto que a adição de água aos componentes secos provoca a hidratação e o aumento de tamanho dos mesmos, reduzindo o espaço poroso do substrato (Bailey et al., 2000).

Tabela 1. Características químicas dos substratos utilizados na produção das mudas de Eucalyptus grandis e Corymbia citriodora.

\begin{tabular}{|c|c|c|c|c|c|c|}
\hline \multirow{2}{*}{ Substrato } & \multirow{2}{*}{$\begin{array}{c}\text { pH } \\
\mathrm{H}_{2} \mathrm{O} \text { 1:1 }\end{array}$} & $\mathbf{C a}$ & Mg & \multirow{2}{*}{$\begin{array}{l}\text { MO } \\
(\%)\end{array}$} & \multirow{2}{*}{\multicolumn{2}{|c|}{$\begin{array}{lr}P & K \\
\left(\mathrm{mg} \mathrm{dm}^{-3}\right)\end{array}$}} \\
\hline & & \multicolumn{2}{|c|}{$\left(\mathrm{Cmol} \mathrm{dm}{ }^{-3}\right)$} & & & \\
\hline Turfa & 5,8 & 25,9 & 4,7 & 17,0 & 14,4 & 176 \\
\hline Vermicomposto & 6,8 & 22,3 & 8,0 & 15,6 & 76,0 & 800 \\
\hline
\end{tabular}

As sementes de E. grandis e C. citriodora foram obtidas na Estação Experimental de Silvicultura de Santa Maria (Fepagro). Após a assepsia em hipoclorito de sódio, as sementes foram pré-germinadas em placas de Petri sobre papel de germinação umedecido e mantidas em incubadora a $26{ }^{\circ} \mathrm{C}$ no escuro, por um período de cinco dias. Decorrido o período de germinação, as sementes germinadas foram transplantadas para tubetes plásticos de $50 \mathrm{~cm}^{3}$, contendo as diferentes proporções de vermicomposto e turfa. Após o transplante, os tubetes permaneceram em casa de vegetação sobre telado utilizado em viveiros comerciais. A reposição da umidade foi realizada adicionando-se diariamente água destilada aos tubetes. A temperatura e a umidade relativa do ar no interior da casa de vegetação durante a condução do experimento variaram entre $25^{\circ} \mathrm{C}$ e $29^{\circ} \mathrm{C}$ e $59 \%$ e $76 \%$, respectivamente (Termohigrômetro TFA).

As avaliações foram realizadas aos 100 dias após o transplante. Avaliaram-se os parâmetros: altura da planta $(\mathrm{mm})$, biomassa da parte aérea fresca e seca $(\mathrm{mg})$, volume radicular $\left(\mathrm{cm}^{3}\right)$, biomassa das raízes secas $(\mathrm{mg})$ e índice de qualidade de Dickson (IQD).

Para a determinação da biomassa da parte aérea fresca e seca, as plantas foram cortadas no nível do substrato. Em seguida, foi pesada a parte aérea, caracterizando a biomassa da parte aérea fresca. As raízes foram separadas do substrato e lavadas com água destilada. O volume radicular foi obtido pelo método de deslocamento de água, adaptando-se metodologia utilizada para solos (Claessen, 1997). O IQD foi determinado pela fórmula (Dickson et al., 1960): IQD=Biomassa seca total/(Altura/ Diâmetro do caule) + (Biomassa da parte aérea seca/ Biomassa das raízes secas).

Os dados obtidos quanto à altura das plantas, biomassa da parte aérea fresca e seca das plantas, biomassa das raízes secas e ao volume radicular, foram transformados para raiz quadrada de $\mathrm{x}+0,1$ e submetidos à análise de variância e ao teste de médias pelo teste de Scott-Knott a $5 \%$ de probabilidade de erro pelo software Sisvar (Ferreira, 2000).

\section{Resultados e discussão}

Para Eucalyptus grandis e Corymbia citriodora, o substrato constituído de $80 \%$ vermicomposto e $20 \%$ turfa proporcionou maior desenvolvimento da parte aérea das mudas, evidenciado pela maior altura (Figura 1) e pelos maiores valores da biomassa seca da parte aérea (Figura 2).

O tratamento constituído por $80 \%$ de vermicomposto e $20 \%$ de turfa proporcionou aumento na altura das mudas de E. grandis e C. citriodora de $82 \%$ e $43 \%$, respectivamente, em relação ao tratamento controle.

Cardoso Júnior et al. (1999), avaliando a dosagem ideal de vermicomposto, obtido a partir de lodo de esgoto urbano, misturado à casca de Pinus sp., observaram que a proporção de $60 \%$ de vermicomposto e $40 \%$ de casca proporcionou maior altura de mudas e peso seco radicular e aéreo de plantas de E. grandis.

$\mathrm{Na}$ espécie $E$. grandis, a adição de vermicomposto à turfa nas proporções de $20 \%$ a $60 \%$ não apresentou diferença significativa quanto à altura das mudas (Figura 1A). As respostas nas espécies E. grandis e C. citriodora quanto à altura das mudas em substratos à base de vermicomposto corroboram com as obtidas em plantas de Eucalyptus camaldulensis e Pinus elliottii (Caldeira et al., 2000), Hovenia dulcis (Vogel et al., 2001) e Acacia mearnsii (Caldeira et al., 2003), embora, para estas espécies, os testes tenham ocorrido em substratos contendo proporções de até $40 \%$ de vermicomposto na mistura. 


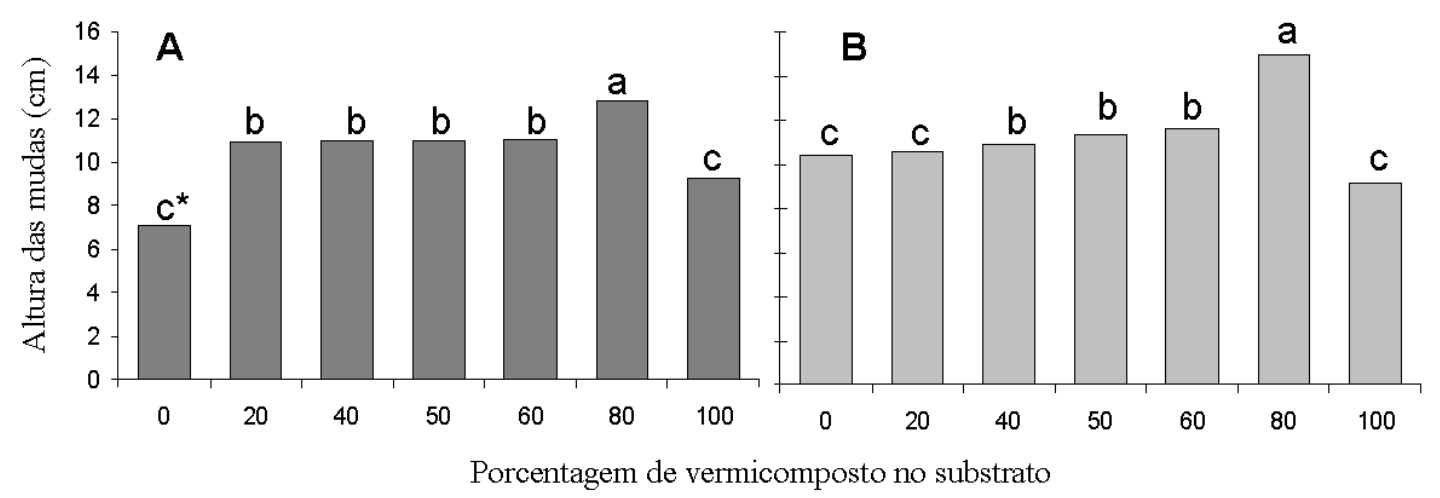

Figura 1. Altura das mudas de Eucalyptus grandis (A) e Corymbia citriodora (B) cultivadas em substratos compostos por diferentes proporções de vermicomposto e turfa. *Médias seguidas de mesma letra não diferem entre si pelo teste de Scott-Knott a 5\% de probabilidade de erro.

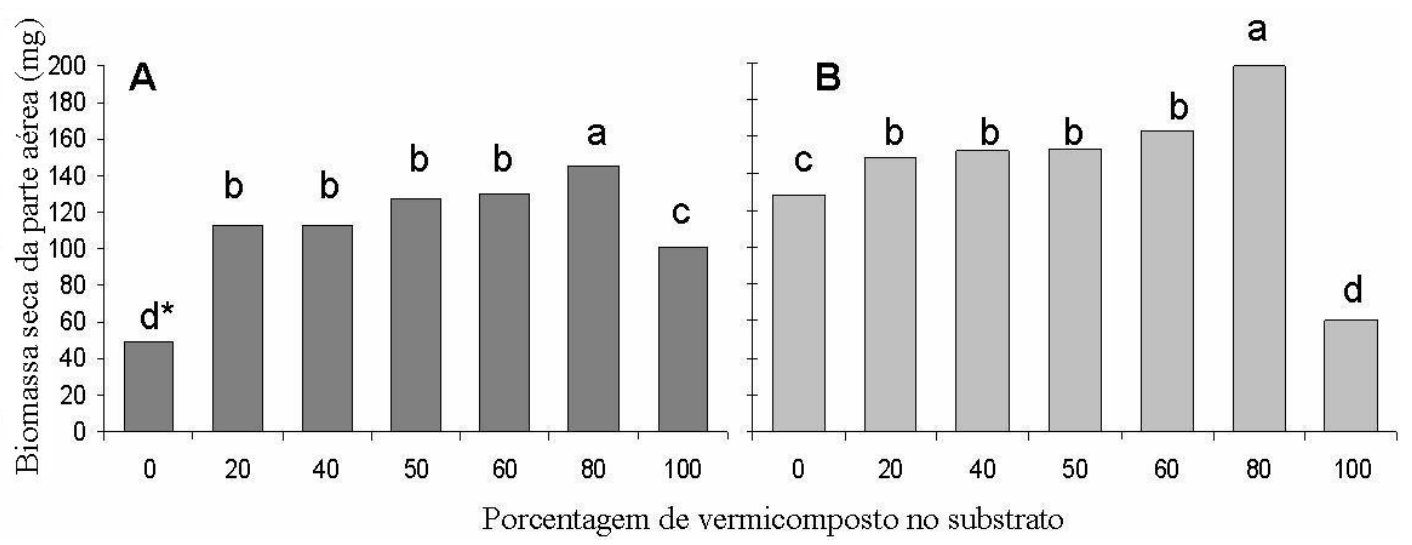

Figura 2. Biomassa seca da parte aérea das mudas de Eucalyptus grandis (A) e Corymbia citriodora (B) cultivadas em substratos compostos por diferentes proporções de vermicomposto e turfa. *Médias seguidas de mesma letra não diferem entre si pelo teste de Scott-Knott a 5\% de probabilidade de erro.

Possivelmente, esta resposta esteja relacionada à necessidade de nutrientes requerida pelas mudas, sendo que, nos substratos compostos por $20 \%$ a $60 \%$ de vermicomposto, o teor de nutrientes presentes pode não ter correspondido a um aumento significativo no nível de disponibilidade destes nutrientes às plantas.

Quanto à biomassa seca da parte aérea das mudas de E. grandis e C. citriodora (Figura 2), observaram-se valores significativamente superiores no tratamento constituído por $80 \%$ vermicomposto e $20 \%$ turfa, seguido pelos tratamentos constituídos por $20 \%$ a $60 \%$ de vermicomposto adicionado à turfa.

Segundo Abreu Júnior et al. (2005), diferentemente da utilização de substratos orgânicos não estabilizados para a produção de mudas, a utilização de vermicomposto não resulta em fitotoxidez, devido à ausência de ácidos orgânicos como os ácidos propiônico, acético e isobutírico. No entanto, no presente trabalho, observou- se que nas espécies florestais avaliadas a utilização de vermicomposto $100 \%$ resultou em desenvolvimento reduzido das mudas, folhas com menor área fotossintética e sintomas de toxidez, evidenciado pelo amarelecimento das folhas inferiores.

Este resultado condiz com o observado por May \& Maranho (2007), em que verificaram que altas concentrações de vermicomposto em mistura com outros substratos provocaram a formação de um menor número de folhas, assim como a formação de folhas de tamanho reduzido.

$\mathrm{Na}$ produção comercial de mudas em tubetes, as características físicas do substrato são fundamentais para prover uma adequada relação entre macro e microporosidade do substrato (Lopes et al., 2005). Segundo Mauad et al. (2004) e Steffen et al. (2010), a adição de vermicomposto em elevadas proporções nos substratos resulta em maior presença de microporos e 
menor presença de macroporos, os quais são responsáveis pelas trocas gasosas nos substratos.

Segundo Kämpf (2000), o cultivo de plantas em recipientes com reduzido volume de substrato leva a uma alta concentração de raízes, exigindo elevado suprimento de oxigênio e rápida remoção do gás carbônico. Assim, o substrato deve apresentar porosidade suficiente para permitir trocas gasosas, evitando falta de oxigenação para a respiração das raízes, e para a atividade microbiana do meio.

A adição de vermicomposto aos substratos para a produção de mudas pode representar aumentos de até $80 \%$ no desenvolvimento das plantas. Segundo os autores, este estímulo no desenvolvimento é resultante de efeitos diretos, devido à presença de alguns hormônios e compostos orgânicos existentes no vermicomposto, e de efeitos indiretos, devido à bioestimulação de microrganismos benéficos às plantas e à influência do vermicomposto na dinâmica de nutrientes e no condicionamento físico do substrato (Arancon et al. 2006).

Para as mudas de E. grandis, a adição de vermicomposto à turfa nas proporções de $20 \%$ a $60 \%$ não apresentou diferença significativa na biomassa seca do sistema radicular das mudas (Figura 3A).

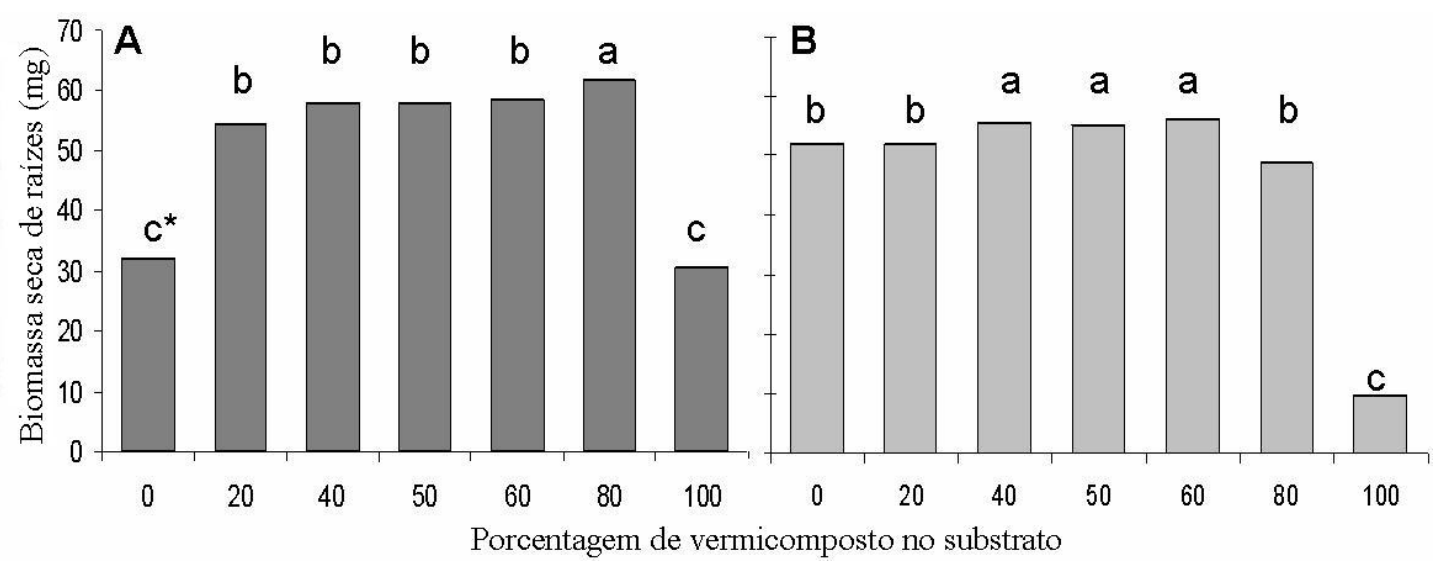

Figura 3. Biomassa seca das raízes das mudas de Eucalyptus grandis (A) e Corymbia citriodora (B) cultivadas em substratos compostos por diferentes proporções de vermicomposto e turfa. "Médias seguidas de mesma letra não diferem entre si pelo teste de Scott-Knott a 5\% de probabilidade de erro.

Entretanto, o tratamento constituído de $80 \%$ de vermicomposto proporcionou crescimento radicular significativamente superior aos demais tratamentos (Figuras 3A e 4A).

Nas mudas de C. citriodora, as adições de $40 \%, 50 \%$ e $60 \%$ de vermicomposto à turfa proporcionaram maior biomassa seca das raízes (Figura 3B). O menor valor da biomassa seca do sistema radicular no tratamento $80 \%$ vermicomposto pode estar relacionado ao direcionamento dos assimilados para um maior crescimento em altura e biomassa seca da parte aérea sem um significativo aumento do crescimento do sistema radicular por estar em um substrato mais rico em nutrientes.
Segundo Taiz \& Zeiger (2004), quando substâncias exógenas reguladoras do crescimento são adicionadas ao meio, há uma reação na fisiologia da planta, que pode ser observada por estímulo ou por inibição do seu crescimento.

Embora os mecanismos bioquímicos envolvidos na ação do vermicomposto sobre o crescimento vegetal ainda não estejam completamente esclarecidos, o efeito da adição deste material a substratos pode ser comparado à adição de auxinas, giberelinas e citocininas (Masciandaro et al., 1997; Rodda et al., 2006), as quais apresentam função relacionada ao crescimento e ao desenvolvimento dos vegetais, agindo como transportadores de açúcares na parede celular e na síntese de glicoproteínas (Taiz \& Zeiger, 2004). 


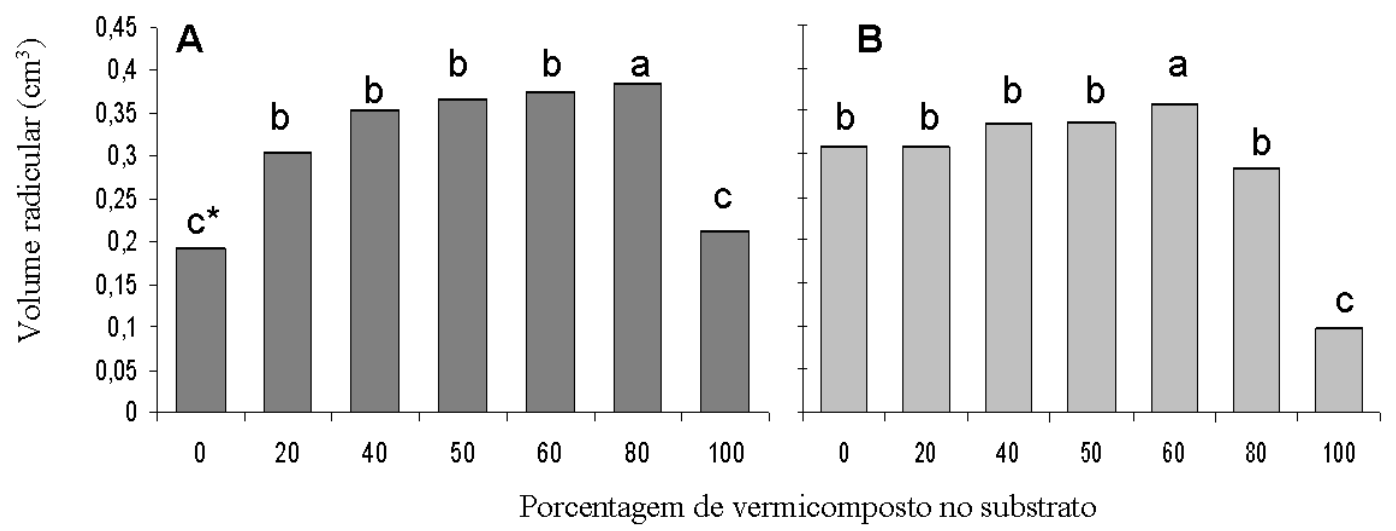

Figura 4. Volume radicular das mudas de Eucalyptus grandis (A) e Corymbia citriodora (B) cultivadas em substratos compostos por diferentes proporções de vermicomposto e turfa. "Médias seguidas de mesma letra não diferem entre si pelo teste de Scott-Knott a 5\% de probabilidade de erro.

O maior desenvolvimento vegetal decorrente do aumento na proporção de vermicomposto adicionado à turfa pode estar relacionado com a ativação da $\mathrm{H}^{+}$-ATPase, exceto para o tratamento $100 \%$ vermicomposto, onde o adensamento do substrato pode ter provocado limitações físicas ao desenvolvimento radicular das mudas. Segundo Rodda et al. (2006), a utilização de vermicomposto como substrato na produção de mudas ativa algumas enzimas transmembranares $\left(\mathrm{H}^{+}\right.$-ATPase) capazes de hidrolisar ATP, gerando energia e ativando mecanismos fundamentais de translocação de íons, o que resulta em maior absorção de macro e micronutrientes pelas raízes.

No caso do vermicomposto, devido à presença de hormônios, os quais apresentam características semelhantes às observadas na auxina, a sua utilização pode resultar em estímulo ao desenvolvimento aéreo da planta e, ao mesmo tempo, em decréscimo do desenvolvimento radicular, visto que parte aérea e raízes apresentam respostas antagônicas de acordo com a concentração destas substâncias no substrato (Taiz \& Zeiger, 2004; Arancon et al., 2006).

O índice de qualidade de Dickson (IQD), utilizado como indicador de qualidade de mudas, avalia a robustez e o equilíbrio da biomassa das plantas, sendo que quanto maior for o valor de IQD, melhor será a qualidade da muda (Vidal et al., 2006).

Em relação ao IQD, os valores obtidos para o E. grandis foram significativamente superiores nos tratamentos constituídos por $60 \%$ e $80 \%$ de vermicomposto. Já para C. citriodora, as adições de
$40 \%$ a $80 \%$ de vermicomposto à turfa proporcionaram os maiores valores deste índice (Tabela 2), evidenciando que as mudas produzidas nestes tratamentos apresentaram maior qualidade.

Tabela 2. Índice de qualidade de Dickson (IQD) das mudas de Eucalyptus grandis e Corymbia citriodora cultivadas em substratos compostos por diferentes proporções de vermicomposto e turfa.

\begin{tabular}{ccc}
$\begin{array}{c}\text { Vermicomposto } \\
\text { no substrato (\%) }\end{array}$ & Eucalyptus grandis & Corymbia citriodora \\
\hline 0 & $0,12 \mathrm{c}^{*}$ & $0,16 \mathrm{~b}$ \\
20 & $0,17 \mathrm{~b}$ & $0,17 \mathrm{~b}$ \\
40 & $0,17 \mathrm{~b}$ & $0,19 \mathrm{a}$ \\
50 & $0,18 \mathrm{~b}$ & $0,20 \mathrm{a}$ \\
60 & $0,20 \mathrm{a}$ & $0,20 \mathrm{a}$ \\
80 & $0,21 \mathrm{a}$ & $0,19 \mathrm{a}$ \\
100 & $0,14 \mathrm{c}$ & $0,05 \mathrm{c}$ \\
\hline $\mathrm{CV}(\%)$ & 3,45 & 4,07 \\
\hline
\end{tabular}

"Médias seguidas de mesma letra não diferem entre si pelo teste de ScottKnott a 5\% de probabilidade de erro.

Segundo Higashi \& Silveira (2004), mudas florestais são consideradas aptas para transplantio após passarem por um período de rustificação que inicia aos 70 a 90 dias e termina, aproximadamente, aos 150 dias. Nesta fase, as mudas tendem a engrossar o caule e expandir as raízes. No entanto, Gomes et al. (2002) estabelecem o período de 90 a 100 dias como o ideal para avaliações quanto à qualidade de mudas florestais do gênero Eucalyptus sp., visto que os valores de IQD se estabilizam nesta fase de crescimento. 


\section{Conclusões}

A utilização de vermicomposto nos substratos usados para a produção de mudas de Eucalyptus grandis e Corymbia citriodora mostrou-se eficiente, proporcionando condições físicas adequadas para a obtenção de mudas florestais de qualidade.

A proporção de $80 \%$ vermicomposto e $20 \%$ turfa mostrou-se eficiente para produção de mudas de Eucalyptus grandis.

Para a produção de mudas de Corymbia citriodora, o maior efeito do vermicomposto de esterco curtido de bovinos criados em sistema de confinamento variou na proporção de $40 \%$ a $80 \%$ adicionado à turfa, proporcionando maior crescimento das mudas dessa espécie.

\section{Referências}

ABREU JÚNIOR, C. H.; BOARETTO, A. E.; MURANOKA, T.; KIEHL, J. de. C. Uso agrícola de resíduos orgânicos potencialmente poluentes: propriedades químicas do solo e produção vegetal. Tópicos em Ciência do Solo, Viçosa, MG, v. 4, 2005. $470 \mathrm{p}$

ANTONIOLLI, Z. I.; GIRACCA, E. M. N.; CARLOSSO, S. J. T.; WIETHAN, M. M. S.; FERRI, M. Iniciação à minhocultura. Santa Maria, RS: UFSM, 1996. 96 p.

ANTONIOLLI, Z. I.; GIRACCA, E. M. N.; BARCELLOS, L. A.; VENTURINI, S. F.; VENTURINI, E. F.; WIETHAN, M. M. S.; CARLOSSO, S. J. T.; BENEDETTI, T., SENHOR, T. C.; SANTI, G. R. Minhocultura e vermicompostagem. Santa Maria, RS: Universidade Federal de Santa Maria, Departamento de Solos, 2002. 24 p. (Boletim Técnico, 3).

AQUINO, M. A.; NOGUEIRA, E. M. Fatores limitantes da vermicompostagem de esterco suíno e de aves e influência da densidade populacional das minhocas na sua reprodução. Seropédica: Embrapa Agrobiologia, 2001. 10 p. (Embrapa Agrobiologia. Documentos, 147).

ARANCON, N. Q.; EDWARDS, C. A.; LEE, S.; BYRNE, R. Effects of humic acids from vermicomposts on plant growth. European Journal of Soil Biology, Braunschweig, v. 42, n. 1, p. 65-69, 2006.

ATIYEH, R. M.; LEE, S.; EDWARDS, C. A.; ARANCON, N. Q.; METZGER, J. D. The influence of humic acids derived from earthworm-processed organic wastes on plant growth. Bioresource Technology, Trivandrum, v. 84, n. 1, p. 7-14, 2002.

BAILEY, D. A.; NELSON, P. V.; FONTENO, W. C. Substrates pH and water quality. Raleigh, NC: North Carolina State University, 2000. Disponível em: $<$ http://www.ces.ncsu.edu/depts/hort/ floriculture/plugs/ph.pdf $>$. Acesso em: 27 nov. 2007.
BENÍTEZ, E.; NOGALES, R.; MASCIANDARO, G.; CECCANTI, B. Isolation by isoelectric focusing of humic-urease complexesfrom earthworm (Eisenia fetida) processed sewage sludges. Biology and Fertility of Soils, Firenze, v. 31, n. 6, p. 489493, 2000.

BROWN, G. G.; EDWARDS, C. A.; BRUSSAARD, L. How earthworms affect plant growth: Burrowing into the mechanisms. In: EDWARDS, C. A. (Org.). Earthworm ecology. Boca Raton: St. Lucie Press, 2004. p. 13-49.

CALDEIRA, M. V. W.; SCHUMACHER, M. V.; BARICHELLO, L. R.; VOGEL, H. L. M.; OLIVEIRA, L. da S. Crescimento de mudas de Eucalyptus saligna Smith em função de diferentes doses de vermicomposto. Floresta, Curitiba, v. 28, n. 1-2, p. 19-30, 2000.

CALDEIRA, M. V. W.; SCHUMACHER, M. V.; OLIVEIRA, E. R. V. de.; WATZLAWICK, F. Influência de vermicomposto na produção de mudas de Pinus elliottii Engelm. Ciências Agrárias e Ambientais, Curitiba, v. 1, n. 3, p. 47-53, 2003.

CARDOSO JÚNIOR, A. R.; BAPTISTA, J.; HOPPE, J. M. Uso de diferentes concentrações de vermicomposto de lodo de esgoto urbano na composição de substrato para a produção de mudas de Eucalyptus grandis Hill ex Maiden. In: ENCONTRO BRASILEIRO SOBRE SUBSTÂNCIAS HÚMICAS, 3., 1999, Santa Maria, RS. Resumos... Santa Maria: Universidade Federal de Santa Maria, Programa de Pós-Graduação em AgronomiaDepartamento de Solos, 1999. p. 175-177.

CLAESSEN, M. E. C. (Org.). Manual de métodos de análise de solo. 2. ed. rev. atual. Rio de Janeiro: EMBRAPA-CNPS, 1997. 212 p. (EMBRAPA-CNPS. Documentos, 1).

DICKSON, A.; LEAF, A. L.; HOSNER, J. F. Quality appraisal of white spruce and white pine seedling stock in nurseries. The Forestry Chronicle, Mattawa, v. 36, p. 10-13, 1960.

EDWARDS, C. A. The use of earthworms in the breakdown and management of organic wastes. In: EDWARDS, C. A. (Org.).

Earthworm Ecology. Boca Raton: St. Lucie Press, 2004. p. 327-354.

EMBRAPA FLORESTAS. Embrapa Florestas: dedicação à pesquisa florestal. Colombo, 2003, 54 p. (Embrapa Florestas. Documentos, 81).

FERREIRA, D. F. Sistemas de análise estatística para dados balanceados. Lavras, MG: UFLA/DEX/SISVAR, 2000. 145 p.

GAMALEY, A. V.; NADPOROZHSKAYA, M. A.; POPOV, A. I.; CHERTOV, O. G.; KOVSH, N. V.; GROMOVA, O. A. Non-root nutrition with vermicompost extracts as the way of ecological optimization. Plant Nutrition: food security and sustainability of agro-ecosystems, Dordrecht, v. 92, p. 862-863, 2001.

GOMES, J. M.; COUTO, L.; LEITE, H. G.; XAVIER, A.; GARCIA, S. L. R. Parâmetros morfológicos na avaliação da qualidade de mudas de Eucalyptus grandis. Revista Árvore, Viçosa, MG, v. 26, n. 6, p. 655-664, 2002.

HIGASHI, E. N.; SILVEIRA, R. L. A. Fertirrigação em viveiros de mudas de Eucalyptus e Pinus. In: BOARETTO, A. E.; VILLAS BOAS, R. L.; SOUZA, W. F. PARRA, L. R. V. (Eds.). Fertirrigação: teoria e prática. Piracicaba, SP: Os Autores, 2004. v. 1. p. 677-725. 
LOPES, J. L. W.; GUERRINI, I. A.; SAAD, J. C. C.; SILVA, M. R. da. Efeitos da irrigação na sobrevivência, transpiração e no teor relativo de água na folha em mudas de Eucalyptus grandis em diferentes substratos. Scientia Forestalis, Piracicaba, SP, v. 68, p. 97-106, 2005.

MASCIANDARO, G.; CECCANTI, B.; GARCIA, C. Soil agro-ecological management: fertirrigation and vermicompost treatments. Bioresource Technology, Trivandrum, v. 59, n. 2-3, p. 199-206, 1997.

MAUAD, M.; FELTRAN, J. C.; CORRÊA, J. C.; DAINESE, R. C.; ONO, E. O.; RODRIGUES, J. D. Enraizamento de estacas de azaléia tratadas com concentrações de ANA em diferentes substratos. Ciência e Agrotecnologia, Lavras, MG, v. 28, n. 4, p. 771-777, 2004.

MAY, D.; MARANHO, L. T. Organização estrutural da folha e influência do vermicomposto no crescimento de Mentha piperita L. Revista Brasileira de Biociências, Porto Alegre, v. 5, supl. 2, p. 624-626, 2007.

MORAES NETO, S. P.; GONÇALVES, J. L. M.; TAKAKI, M. Produção de mudas de seis espécies arbóreas, que ocorrem nos domínios da Mata Atlântica, com diferentes substratos de cultivo e níveis de luminosidade. Revista Árvore, Viçosa, MG, v. 25, n. 3, p. 277-287, 2001.

NDEGWA, P. M.; THOMPSON, S. A. Integrating composting and vermicomposting in the treatment and bioconversion of biosolids.

Bioresource Technology, Trivandrum, v. 76, n. 2, p. 107-112, 2001.

OLIVEIRA, A. P.; ESPÍNOLA, F. E. J.; ARAÚJO, J. S.; COSTA, C. C. Produção de raízes de cenoura cultivadas com húmus de minhoca e adubo mineral. Horticultura Brasileira, Campinas, SP, v. 19, n. 1, p. 77-80, 2001.
KÄMPF, A. N. Produção comercial de plantas ornamentais. Guaíba, RS: Agropecuária, 2000, 254 p.

RODDA, M. R. C.; CANELLAS, L. P.; FAÇANHA, A. R.; ZANDONADI, D. B.; GUERRA, J. G. M.; ALMEIDA, D. L. de; SANTOS, G. de A. Estímulo no crescimento e na hidrólise de ATP em raízes de alface tratadas com humatos de vermicomposto. I- Efeito da concentração. Revista Brasileira de Ciência do Solo, Viçosa, MG, v. 30, n. 4, p. 649-656, 2006.

STEFFEN, G. P. K.; ANTONIOLLI, Z. I.; STEFFEN, R. B.; BELLÉ, R. Húmus de esterco bovino e casca de arroz carbonizada como substratos para a produção de mudas de boca-de-leão. Acta Zoológica Mexicana, Caracas, n. 2, p. 345 - 357, 2010. Número especial.

TAIZ, L.; ZEIGER, E. Fisiologia Vegetal. 3. ed. Porto Alegre: Artmed, 2004. 719 p.

VIELMA-RONDÓN, R.; OVALLES-DURÁN, J. F.; LEÓNLEAL, A.; MEDINA, A. Valor nutritivo de la harina de lombriz (Eisenia foetida) como fuente de aminoácidos y su estimación cuantitativa mediante cromatografia en fase reversa (HPLC) y derivatización precolumna con o-ftalaldehído (OPA). Ars Pharmaceutica, Granada, v. 44, n. 1, p. 43-58, 2003.

VIDAL, L. H. I.; SOUZA, J. R. P. de; FONSECA, E. de P.; BORDIN, I. Qualidade de mudas de guaco produzidas por estaquia em casca de arroz carbonizada com vermicomposto. Horticultura Brasileira, Campinas, SP, v. 24, n. 1, p. 26-30, 2006.

VOGEL, H. L. M.; SCHUMACHER, M. V.; BARICHELO, L. R.; OLIVEIRA, L. da S.; CALDEIRA, M. V. W. Utilização de vermicomposto no crescimento de mudas de Hovenia dulcis Tthunberg. Ciência Florestal, Santa Maria, RS, v. 11, n. 1, p. 21-27, 2001. 